\title{
The 'nature' of urban sustainability: private or public greenspaces?
}

\author{
C. Bernardini \& K. N. Irvine \\ Institute of Energy and Sustainable Development, \\ De Montfort University, UK
}

\begin{abstract}
Addressing urban sustainability requires an understanding of the psychological experience of place. This study explores the relationship between people and two types of nature. Semi-structured interviews with 40 householders in a UK city suggest remarkable differences in how gardens and public greenspaces contribute to residents' sense of self. Control and private space emerged as distinguishing factors. Having a connection with nature positively affects perceptions of ecological value; this value corresponded with environmental concern. Findings support the proposition that greenspaces are meaningful for people-environment relationships with implications for promoting quality social and ecological urban settings.
\end{abstract}

Keywords: place identity, environmental perception, urban sustainability, environmental concern, greenspaces, gardens, parks, biodiversity.

\section{Introduction}

The contribution of nature to urban social sustainability, particularly to residents' relationship to place, has received little attention. While research has explored psychological processes leading to place identity (e.g. Uzzell et al [1]; TwiggerRoss \& Uzzell [2]), few have examined the process in terms of urban nature. What research there is, centres on public greenspaces (e.g. Bell et al [3]); private areas remain largely under-studied. The purpose of this study was to explore the similarities and differences for place identity (PI) processes and environmental representation (ER) in relation to private gardens and public greenspaces. 


\section{Place identity integrated model (PIIM) and ER}

The idea of 'place' emerges from the interaction of three aspects of a humanenvironment setting: physical elements, activities and cognitive experience (Canter [4]). A place is likely to encourage identification when it becomes meaningful, namely when the individual finds in it symbols significant for the self. Place identity is defined as that part of an individual's personal identity based on or built upon the physical and symbolic features of the place (Proshansky et al [5]). Identity process theory (Breakwell [6]) suggests that an individual absorbs information from the environment that is placed into preexisting mental structures, continuously adjusted and subsequently evaluated so as to attribute meanings to the new elements.

The foundation for the PIIM was Breakwell's [6] four principles considered salient for PI development: distinctiveness, continuity, self-esteem and selfefficacy (see Table 1). The literature review suggested additional relevant concepts which have not been explored in relation to greenspaces. Much of the empirical research on PI has focused either on the social aspects of places or on the physical factors involved in social settings. Research on sense of place for natural spaces mainly investigates landscape preferences or attachment. Our study is framed by an integrated model that includes overlooked elements; all relevant constructs are presented and defined in Table 1 .

Given the focus on PI and the natural environment people's perception of nature were also of interest. Research has explored landscape preferences for public greenspaces centring on attitude and behaviour (e.g. Williams \& Cary [7]) and emotional attachment (Ryan [8]). Little research has explored peoples' understanding of urban biodiversity; this type of information is essential in the urban context where human actions affect natural ecosystems (Savard et al [9]).

ER embraces the perception, knowledge and experience of nature (Ryan [8]) as well as the meanings attached to natural features (Henwood \& Pidgeon [10]). Perception is an overall notion of the place ensuing from the sensory information. Knowledge concerns the understanding of natural features and processes; experience refers to the personal familiarity with the natural world developed through contact and activities. Meanings attributed to nature are explored in terms of symbolic qualities (e.g. level of naturalness), ecological value (e.g. level of biodiversity) and environmental concern (e.g. for wildlife).

\section{Method}

\subsection{Study area and participants}

The study was conducted from June to July, 2004 in Leicester, UK. The sample consisted of 40 householders recruited using the following selection criteria: city location (e.g. proximity to parks); gender; type of garden (e.g. size, design), house type (e.g. semi-detached); ethnicity. Seventy-five percent were women; ages ranged from 26 to $67(\mathrm{~m}=43)$. The majority was White-British $(72 \%)$ with $25 \%$ Asian-British. 
Table 1: $\quad$ Psycho-social constructs within PIIM.

\begin{tabular}{|l|l|}
\hline Construct & Definition \\
\hline Distinctiveness & $\begin{array}{l}\text { Being associated with a place that makes one feel unique } \\
\text { (e.g. Breakwell [6]; Hummons [11]) }\end{array}$ \\
\hline Continuity & $\begin{array}{l}\text { Desire to preserve sense of self over time \& space } \\
\text { (Breakwell [6]) } \\
\text { PrC-Physical environment as reference for past action \& } \\
\text { experience at individual \& collective level } \\
\text { PcC-General \& transferable characteristics of a place that } \\
\text { enable individual to maintain continuity from place to } \\
\text { place }\end{array}$ \\
\hline Pelf-Esteem & Personal feeling of worth (Breakwell [6]) \\
\hline Self-Efficacy & Belief in one's own ability (Breakwell [6]) \\
\hline Pride & $\begin{array}{l}\text { Positive evaluation of a place to which one feels } \\
\text { associated (Twigger-Ross \& Uzzell [2]) }\end{array}$ \\
\hline Symbolic Meanings & $\begin{array}{l}\text { Significance linked to qualities of place (e.g. Stedman } \\
\text { [12]; Relph [13]) }\end{array}$ \\
\hline Sense of Community & $\begin{array}{l}\text { Feeling of belonging to community (e.g. Kim \& Kaplan } \\
\text { [14]) }\end{array}$ \\
\hline Manageability & $\begin{array}{l}\text { Quality of place in facilitating organisation of one's life } \\
\text { \& achieving one's purposes (e.g. Winkel [15]) }\end{array}$ \\
\hline Satisfaction & Overall judgement of quality (e.g. Stedman [12]). \\
\hline Social Imageability & $\begin{array}{l}\text { Collective social meanings \& perception of place } \\
\text { (Stokols \& Shumaker [16]) }\end{array}$ \\
\hline Control & $\begin{array}{l}\text { (e.g. Syme et al [17]) } \\
\text { Perceived ease of access to place } \\
\text { Real \& symbolic possession of place } \\
\text { Perceived or real ability to use place as desired }\end{array}$ \\
\hline Action & $\begin{array}{l}\text { Perceived ability to regulate interaction with others (e.g. } \\
\text { Bonnes \& Secchiaroli [18]) }\end{array}$ \\
\hline Activities & Experiences within the place (e.g. Ryan [8]) \\
\hline
\end{tabular}

\subsection{Data collection and analysis}

Semi-structured interviews utilised open-ended questions developed using the PIIM as a framework to explore PI. Questions about ER were created based on the literature review and addressed perception, beliefs, and attitudes toward the environment as well as behaviours. Participants were asked about both their home garden and public greenspaces; the local area in PI was also considered. Interviews were tape recorded with permission then transcribed verbatim into written text. Analysis consisted of multiple reviews of individual transcripts and coding, a procedure that assigns labels to textual material with the aim of distinguishing relevant phenomena, collecting examples of those phenomena, and organising data into a structure that identifies similarities and differences. Private and public greenspaces were analysed separately; relationships among resulting PI and ER elements were explored for each place.

For analysis of PI we used the PIIM concepts as a priori labels in initial coding. An iterative process categorised these a priori labels into 'themes' and 
'facilitators' as determined by the perceived importance in the identification process. Themes were defined as the values that people perceived as crucial for their life; they are the prime goals which directly feed into self identity. Facilitators were temporary targets or devices that assist the prime goals and depend mainly on the place-specific context; they indirectly contribute to the identity process. Themes and facilitators were sub-categorised into main and minor elements based on prevalence within the data as determined by both the level of relevance (i.e. frequency across sample and amount of text) and the level of interconnection (i.e. number of linkages among elements). The higher the level of interconnection, the higher the influence of the concept on the overall structure and hence on the process of identification.

With respect to ER a grounded theory approach (Strauss \& Corbin [19]) was used for exploration of the cognitive processes and narrative descriptions of nature in the home garden and public green areas. Interviews were coded inductively allowing the coding scheme to emerge from the data. Initial coding used participant's own words (e.g. concern for wildlife, concern for chemical products) as labels; these labels were refined and clustered into broader themes (e.g. environmental concern). This process of abstraction identified core themes relevant to the perception of the urban natural environment. Main and minor themes and facilitators were identified using the same criteria outlined above.

\section{Results and discussion}

\subsection{Place identity and environmental representation in the garden}

Nine PI themes emerged, six of which were main themes, including Breakwell's four principles (i.e. Distinctiveness, Self-Esteem, Self-Efficacy, Continuity), Satisfaction and Symbolic Meanings; the remaining three, Pride, Activities and Privacy, were minor. Two main facilitators, Manageability and Control, were identified (see Figure 1). For ER two themes emerged: Perception and Concern. Environmental concern was often discussed as an aspect of distinctiveness and self-efficacy therefore it is also presented in the context of these two themes.

Seventy-one percent of the sample expressed a positive self-reported identification with the garden, confirming that people do identify with their garden. This identification process was primarily discussed in terms of expression of creativity, an aspect of distinctiveness, and the freedom to act on the place, an aspect of control.

\subsubsection{Distinctiveness, self-esteem, self-efficacy and continuity}

People perceived their relationship with the garden as special and distinct from relationships with other places, confirming that the garden was indeed used to maintain personal distinctiveness in the identity process. However, because the garden was used and modified to reflect the individual's uniqueness rather than provide a distinctiveness that people would use to differentiate themselves analysis suggested a further division between a 'place' and a 'personal' distinctiveness. People did not identify themselves as a gardener or as an 
environmentalist because they had a garden, quite the opposite; a garden reflected an individual's identity as gardeners or environmentalists. Thus people used their personal qualities (i.e. personal distinctiveness) to distinguish themselves from others and the attributes of the place (i.e. place distinctiveness) were used to confirm their personality. This suggests that affirmation of personal distinctiveness is essential for identification with a place precisely because it is the personal distinctiveness that makes the garden unique. Accordingly, place identification is encouraged by the features of the garden that are consistent with the unique qualities of the individual.

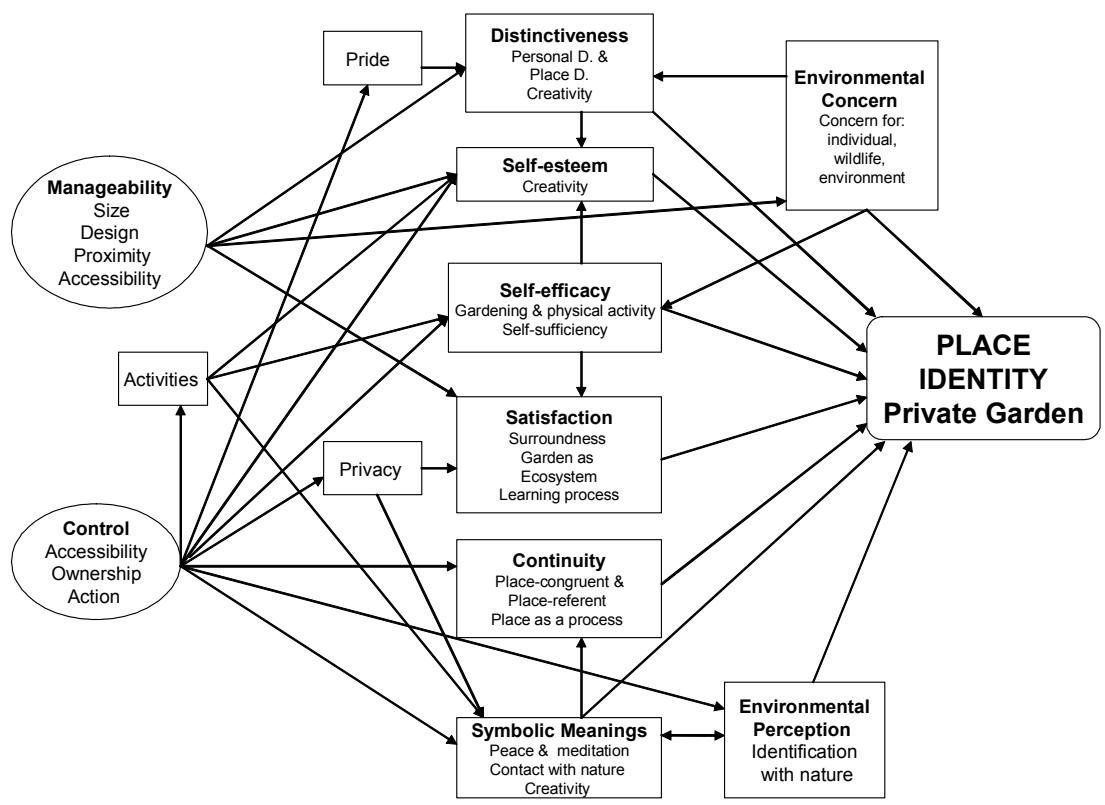

Figure 1: Constructs relevant to PI process and ER for private gardens. Boxes represent themes; circles facilitators; in bold are main elements.

Participants used two strategies to differentiate themselves and their garden from others. Some used categories, such as 'I am a typical middle class academic type' (Interview 8) while others used comparison, for example, 'when I go to other people's houses I notice what their garden it is like compared to mine' (Interview 30). Environmental concern was often used by respondents to distinguish themselves and their garden from others. Most participants who expressed environmental concern reflected or tried to reflect it in their garden; for a small number the home garden was the only place where they could fully express the personal sense of responsibility for environmental issues.

The opportunity to put environmental concern into practice was often dictated by the physical characteristics of the garden. Size, design, proximity and 
accessibility were identified as aspects of garden manageability that could either hinder or facilitate the expression of personal concern for the environment. Garden size and design were relevant for people in expressing their philosophy (e.g. environmentalism) and pursuing their expectations, for example a small size and simple design allowed people to have free time to purse other hobbies. Proximity and accessibility, both physically and psychologically, were incentives to increase the effort put into those activities and to make the garden reflect one's personality. Ultimately the manageability of the place enabled people to express their self identity and personal creativity as well as facilitated and encouraged environmentally friendly behaviours, which contributed to distinctiveness and identification.

Self-efficacy, another major theme, was greatly present in the conversations. Participants described the sense of achievement as a dynamic state; it is not a matter of success or failure but of challenge and experimentation. The ability to tend the garden and to identify plant and animal species was described as a series of steps which, by encouraging contact with nature, improved one's knowledge of the garden and the natural world.

The sense of self-efficacy combined with a desire for psychological, ethical and economic independence also led some participants to see their garden as the key to self-sufficiency. Seen mainly as material independence, self-sufficiency was associated with, for example growing one's own vegetables and composting. This idea of self-sufficiency was consistent with the perception of distinctiveness often associated with or expressed as personal environmental concern.

The concept of self-esteem proved highly relevant for its strong connection with both distinctiveness and self-efficacy. Data suggest a close connection between self-efficacy and self-esteem. For example, people perceived a high sense of achievement from the results obtained from the activity of gardening and from having wildlife in a small space. This sense of self-efficacy was often associated with an optimistic mood and a sense of worth, both of which describe the feeling of self-esteem.

People also manifested a positive evaluation of themselves when they had the opportunity to express their personal creativity in the garden. The opportunity to be creative in the garden was perceived by respondents as the freedom to express their personality in artistic and original ways, confirming that the process of identification relies on the expression of the self. The wide range of activities performed in the garden, such as artistic and recreational activities, reading, sleeping, sunbathing, socialising, playing, collecting plants to dry, relaxing, meditating, DIY, working, confirmed that the garden helped people lift their selfesteem and express themselves. The achievement of such creativity makes the individual feel capable and the perception of personal capacity nourishes the personal sense of worth. The expression of personal creativity was a recurrent topic across the sample that links several PIIM themes especially self-esteem, distinctiveness and symbolic meanings. The process of self-esteem was facilitated by both manageability, which supported people's effectiveness and creativity in the garden, and control, which allowed people to act on the place and feel efficient. 
Breakwell's fourth principle is continuity; findings confirmed that maintenance of continuity of the self through the garden promotes identification with the place. Place-referent and place-congruent continuity were both relevant to PI with the garden. The former was expressed by the desire to stay in the same garden to which participants had attached meanings and memories over time. Place-congruent continuity, more common in discussion, captured the need to modify the place in order to reproduce characteristics of other important places (e.g. childhood garden, countryside).

Control was also important in preserving place-congruent continuity. Data showed that participants needed to have control over the place, both in terms of ownership and action, and that the many and frequent changes made to gardens were often an attempt to preserve a place-congruent continuity. The use of the garden to maintain a continuity with an identity which changes over time and experiences supports the idea of 'place' as a process, where the meanings attributed to the place change as the person changes and the preservation of continuity is an ongoing process (Smaldone et al [20]). Continuity of the selfconcept often relies on the specific objects to which people attach symbolic meanings because these objects represent a link with the past. Plants frequently had emotional meanings that helped preserve the continuity of self-concept by linking people to objects, people or experiences from their past.

\subsubsection{Satisfaction and symbolic meanings}

Perceived satisfaction was an aspect highly regarded in the person-garden relationship. Although self-reported satisfaction was dependent on personal interpretation and experience, it was generally positive $(65 \%)$; this was explained by the high general manageability and privacy perceived in the garden. Participants described privacy in terms of the sense of being unobserved by others but also as the ownership of the place which enabled restricted access. Participants also referred to the self-efficacy achieved through physical activity in the garden as enhancing satisfaction. Two key elements emerged from the data on satisfaction: people referred to the pleasure obtained by the sense of 'surroundness' and the perception of the garden as a small evolving ecosystem to observe. The feeling of being surrounded by nature also helped people reduce a sense of 'urban claustrophobia'.

To comprehend the process that leads people to establish significant relationships with places, the research examined the kinds of meanings people attributed to the garden and how these meanings had been attached to the place. Interviews revealed that relaxation, peace and meditation were the most valuable things obtained from the garden (mentioned by $70 \%$ of the sample) followed by the sense of privacy and the opportunity to be in close contact with the natural world. The development of those feelings over time and experience made their garden a meaningful place. The sense of privacy also enabled people to express personal creativity. Contact with nature and a perceived sense of wilderness were highly valued aspects of the home garden in part because of the associated symbolic meanings such as the perceived rhythm of life. 


\subsubsection{Environmental perception and environmental concern}

Analysis on environmental perception revealed that the garden, while involved in the process of PI, also generated a specific 'identification with nature'. This identification often depended on the experience, which is determined by the range of activities engaged with nature in the garden. The experience seemed to go through two decisive phases, a sensorial perception of the physical factors which just involved observation of nature, followed by action (control), which aimed at modifying the place.

Environmental concern was felt by participants at three levels: personal, wildlife and environment. The main concern expressed in relation to the garden was described as the threat represented to local wildlife from the use of chemical products. Then there was the perceived threat for personal health; ultimately the participants expressed a vague concern for the environment.

\subsubsection{Garden summary of findings}

Findings demonstrated that the home garden plays an important role in defining and expressing self identity; the place was actively used to create, maintain and enhance the individual's personality. There was evidence of people's longing for a place which reflected who they are as a person, confirming that the expression of self identity was a priority for the relationship with the garden. Time was an important aspect of the person-garden relationship. Satisfaction was perceived as time dependent especially when the time was associated to the physical experience of the place. The quantity and the quality of time spent in the garden were both aspects which enabled people to relax and to feel part of the natural world. Control, mainly exerted though privacy and activities, proved to be crucial for three elements of the model, continuity, satisfaction and symbolic meanings.

The need for a physical experience with the environment, expressed through a number of different activities, was a linking factor between many elements in the model. This was also reflected in the role of action (control) for the main themes of self-esteem, self-efficacy, continuity, satisfaction, environmental concern and symbolic meanings. This suggests that experience with nature is an essential element in garden PI. Ultimately, these results confirm that the concept of place can be considered a process and that identification with the garden is supported by dynamic elements such as time, space and experience.

\subsection{Place identity and environmental representation in public greenspaces}

Analysis revealed five PI main themes three of which, Meanings, Activities and Physical Properties were part of Social Imageability (see Table 1); the other two, Satisfaction and Sense of Community, are related to identification with the local area. One minor theme (i.e. ER) and one facilitator (i.e. Manageability) were also identified. Results are presented in Figure 2.

\subsubsection{Social imageability}

Social imageability represents participants' overall perception of public greenspaces as expressed by the meanings attributed to the place, the perception 
of its physical attributes and the physical interaction with it. Conversations identified four topics of general concern and the way people spoke about public greenspaces reflected the three aspects of imageability. The ideal user and the function of parks were the first two issues and answered the questions of what meanings people attributed to and what kind of interaction (activity) they established with the place. Meanings are especially relevant for what people believe public greenspaces should be like, what purposes they should fulfil and whose needs they should meet. Problems and characteristics, two aspects that described public greenspaces' physical properties, resulted from participants' experience and perception of greenspaces that they had visited or knew.

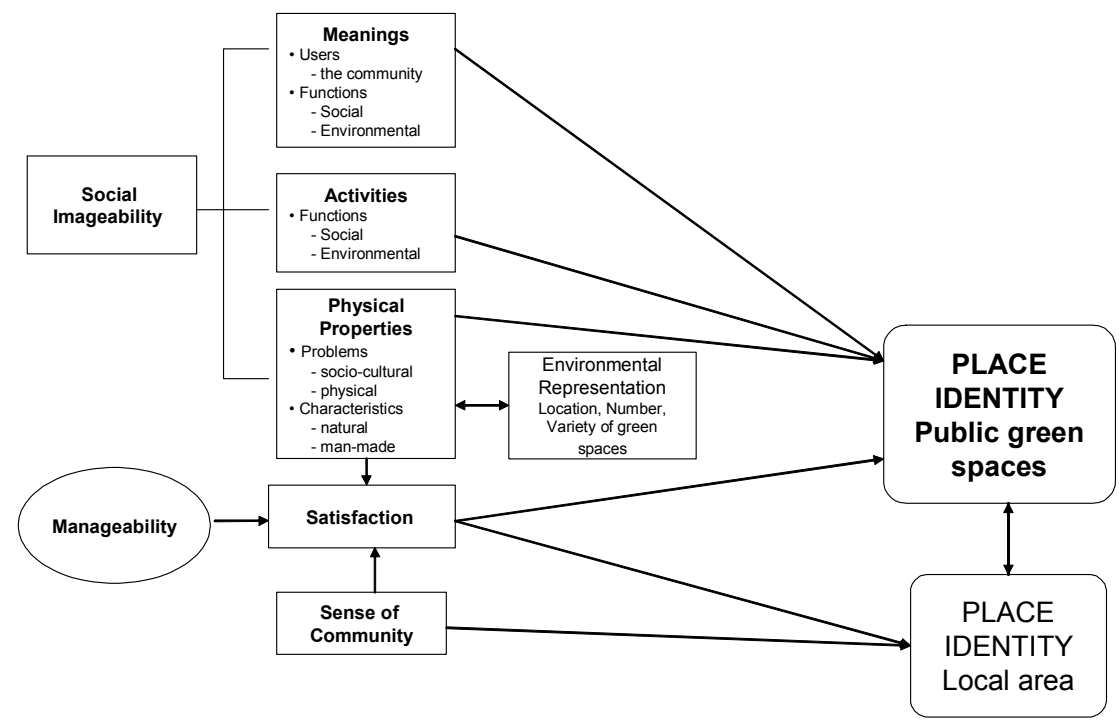

Figure 2: $\quad$ Constructs relevant to PI process and ER for public greenspaces. Boxes represent themes; circles facilitators; in bold are main elements.

With respect to the ideal user, participants agreed that everybody should benefit from urban greenspaces; parks should be available and accessible to all citizens and address the needs of the whole community. There was however a common understanding that a single place cannot satisfy all the needs of a varied and complex community. Emerging from the conversations was the idea of a network of greenspaces differentiated from yet linked with each other, both physically and functionally, that could address differing expectations and provide all facilities required for enjoyment by different users.

The main function attributed to public greenspaces was to provide outdoor spaces for people with no or only small gardens. A few participants however argued strongly that public greenspaces are places to socialize regardless of the availability of private gardens. In fact, this social function of greenspaces 
emerged as a highly valued element. Interestingly, despite this apparent value of parks for socialising participants also pointed out that city parks were scarcely used. The reasons why public greenspaces are valued yet underused is tied to participants' perceptions of the local area and the sense of community.

Meeting people, gathering and neighbourliness were all aspects attached to greenspaces. These places were considered to be community meeting places 'for people to collectively enjoy and appreciate' (Interview 28). Greenspaces were also observed to have a role in social control without which 'people would feel claustrophobic and start being more likely to cause revolutions' (Interview 2), especially in densely urbanised contexts. Having immediate access to a place that provides a sense of calmness and relaxation was perceived as helpful in preventing stress and violent behaviours. Additional perceived benefits of public greenspaces include provision of free recreation, enhancement of a healthy lifestyle through contact with nature and physical activities as well as its contribution to emotional well-being. The emotional benefits people gained include happiness, relaxation and tranquillity.

Findings showed an apprehension about the balance between the built and natural environment that was primarily associated with a perceived urban claustrophobia. In the words of one participant the primary function of parks is 'bringing a bit of countryside into the city...so that it's not just all houses and roads' (Interview 9). This need for balance was also related to participants' concern for wildlife. The environmental function that people attributed to parks was supported by the knowledge that wildlife in private gardens depended on the way that parks, patches of scrub lands and neglected areas provided protection for animals and plants. Overall, the meanings that people attributed to public greenspaces depicted a collective image of parks as highly versatile places that reflect the complexity of the individual and the community.

Despite a wide range of identified functions and benefits participants raised a number of problems. First among these was the common perception that people are not inclined to use parks. The respondents indicated two reasons. First, there is an ethno-cultural component represented by a tendency among British to keep to themselves. Several participants did note, however, that park usage tended to be higher among non-white British (e.g. Asian-British). The second factor concerned a perceived inadequacy of parks. Participants felt that public greenspaces in the UK are scarce and badly designed; they often couched these discussions in terms of the restrictive rather than encouraging policy (i.e. what not to do vs. what you can do) put into place by planners and policy makers.

Ultimately, the shortcomings observed led the discussion to the perception of the physical characteristics of the place. Properties that people perceived and expected to be provided by public greenspaces can be distinguished between facilities for users and natural qualities. Recreational facilities should reflect the variety of users' needs; in terms of natural attributes data revealed a high desire for variety in plant species and in design.

\subsubsection{Environmental representation}

Participants referred to a wide range of open spaces: parks, street greenery, churchyards, cemeteries, scrubland, allotments, meadows, the area along the 
canal, the fields on the outskirt of the city and the countryside. Three key aspects emerged from the evaluation: location in the area, number and variety of places available. The location often concerned the proximity to the house especially in terms of walking distance. The number of greenspaces was often mentioned in association with the variety available; data suggest that people judged the overall quality of greenspaces in the area based on a combination of the number of places available and their environmental value. For those who go to the park specifically for being in contact nature the variety of flora and fauna was very important and the natural designs were generally preferred to artificial ones.

\subsubsection{Satisfaction}

Satisfaction with public greenspaces mirrored the discussion on social imageability; satisfaction levels reflected the mismatch between the ideal qualities of the place and the perception of its physical properties. Satisfaction was discussed in terms of aesthetics (e.g. flower design), manageability and perceived wilderness. Manageability was expressed in terms of size, proximity and the variety of nature and facilities available. Size and proximity were discussed as interconnected aspects; it is good to have a big park but it is equally necessary to have small greenspaces in close proximity. With respect to perceived wilderness the highest appreciation was for the openness and wilderness of large parks; however there was a shared opinion that the city needed more small, enclosed and unstructured pockets of vegetation to support wildlife.

\subsubsection{The local area and public greenspaces}

Participants' dialogue about public greenspaces was often embedded in the broader context of the local area. Two aspects of PI with the local area, satisfaction and sense of community, have important implications for identity with public greenspaces. While findings on public greenspaces showed an attribution of high social significance but a low level of identification, findings on the local area were the opposite, showing a high level of identification with the local community but a very weak social network. Data confirmed that satisfaction with the local area was highly influenced by participants' perceived sense of community. Results revealed limited social interactions within the local area and the propensity for low-committing relationships with neighbours and the local community.

Nevertheless, a desire for a greater sense of community was present, expressed by some participants as the perception of the local area as 'an urban village' (Interview 13) where people felt part of the community through, for example use of local shops. Participants identified the presence of public parks as crucial in promoting a sense of community and creating neighbourliness through the repeated-ness of meeting the same faces.

\subsubsection{Public greenspaces summary of findings}

The meaning and purposes people attributed to public green places showed an anthropocentric view, with ecological benefits for the environment expressed only in terms of implications for humans: this suggested that people need to be in 
contact with the place to perceive an advantage. For some participants parks had no impact on their lives because they did not visit them; others felt that parks had lost relevance since they stopped visiting them. Data suggested that benefits come mainly from the proximity and personal experience of the space. In general participants valued the system of local parks as a whole as a way to provide high quality resources in terms of nature and facilities; the preference is given to a high number of greenspaces of different size, vegetation and design. All together they should provide good variety in plant species and natural landscapes in order to accommodate the community's varied needs.

Interviews showed a positive identification with the local area $(71 \%$ of the sample). Identification mainly involved the local community (sense of community) and it was expressed by the location in the city (centre vs. suburb), which reflected personal character and needs.

\section{Conclusions and implications}

This study investigated the psychological experience of urban nature. Focusing on the processes and linkages among the physical setting, human activities and the meaning associated with place, analysis revealed remarkable differences in how private gardens and public greenspaces contribute to residents' PI as well as residents' perceptions of nature (see Figures 1 and 2).

All four of Breakwell's PI principles were important in the identity process for private gardens. Distinctiveness, self-esteem and self-efficacy were interconnected by the desire to express personal creativity through the garden and by one's environmental concern. The presence of continuity, another main theme, confirmed that people use gardens to preserve the self-concept across time and space. The attachment of meanings to garden objects was a prime way in which people maintained continuity. In fact the attribution of symbolic meanings enabled participants to establish significant relationships with their garden making it a significant place in their lives. The sense of peace, the contact with the natural world and the privacy offered, all allowed respondents to make their garden a place with which they could identify.

Continuity and satisfaction (the sixth main theme) with the garden suggested that the relationship between people and the place is dynamic, confirming the idea of place as a process (Smaldone et al [20]). The close and physical contact with nature, facilitated by the physical activity in and the control over the garden, emerged as a very important aspect of the person-garden relationship. Data suggested that this contact encouraged identification with nature indicating that ER is a decisive aspect of the identity process.

The identity process for public greenspaces was quite different. First, it is noteworthy that none of Breakwell's principles of PI were present in the model. Control as a facilitator was also noticeably absent. Instead, social imageability and satisfaction were identified as the main themes involved in the identity process. All three principles of imageability were relevant, discussed in terms of users, functions, problems and characteristics of public greenspaces. Manageability played a similar contributory role for satisfaction with size and 
proximity of public greenspaces as of gardens. Interestingly, the value of variety, both in terms of natural environments and facilities, was a new dimension of manageability relevant for parks. Overall, the perception of the physical attributes of public greenspaces seemed to confirm what emerged from the findings on the ideal function attributed to parks. Participants felt that a whole system of local parks should offer high quality resources in terms of nature and facilities. The preference was for a high number of greenspaces of different size, vegetation and designs, all together they should provide good variety in plant species and natural landscapes. A final difference of significance is the perception that public greenspaces are important places for socialising. They can play a role in creating a sense of community, which appears to be lacking for the local area.

This study suggests that the psychological and social factors involved in the identity processes are different for private and public greenspaces. Findings also demonstrate that the components of PI for the garden are more solid and deeprooted than those involved in the identification with public greenspaces. This is validated by the greater identification with the garden; the identification with the public spaces is lower and appears dependent on aspects specifically related to the local area, such as sense of community.

In conclusion the identity process with the public greenspaces needs to be explored within the local area given that the local area, as a community located in a physical setting, is the place with which people tend to identify. The PIIM for the garden demonstrates that there are psychological and social factors which are key for the identity process and which are not present for the public spaces. This research points out the importance of understanding the complexity of the factors behind the PI process associated with private and public greenspaces as they have to be considered in re-thinking and planning modern cities which are socially and environmentally sustainable.

\section{References}

[1] Uzzell, D., Pol, E. \& Badenas D., Place identification, social cohesion and environmental sustainability. Environment and Behavior, 34(1), pp. 2653, 2002.

[2] Twigger-Ross, C.L \& Uzzell, D.L., Place and identity processes. Journal of Environmental Psychology, 16, pp. 205-220, 1996.

[3] Bell, S., Morris, N., Findlay, C., Travlou, P., Montarzion, A., Gooch, D., Gregory, G. \& Thompson, C.W., Nature for people: The importance of greenspaces to East Midlands communities, (Research Report Number 567), English Nature: Peterborough, 2003.

[4] Canter, D., The Psychology of Place, Architectural Press: London, 1977.

[5] Proshansky, H., Fabian, A. \& Kaminoff, R., Place-identity: Physical world socialization of the self. Journal of Environmental Psychology, 3, pp. 57-83, 1983.

[6] Breakwell, G.M., Social Psychology of Identity and the Self-concept, Surrey University Press: Surrey, 1992. 
[7] Williams, K.J. \& Cary, J., Landscape preferences, ecological quality, and biodiversity protection. Environment and Behavior, 34(2), pp. 257-274, 2002.

[8] Ryan, R.L., Exploring the effects of environmental experience on attachment to urban natural areas. Environment and Behavior, 37(1), pp. 3-42, 2005.

[9] Savard, J.L., Clergeau, P. \& Mennechez, G., Biodiversity concepts and urban ecosystems. Landscape and Urban Planning, 48, pp. 131-142, 2000 .

[10] Henwood, K. \& Pidgeon, N., Talk about woods and trees: threat of urbanization, stability, and biodiversity. Journal of Environmental Psychology, 21, pp. 125-147, 2001.

[11] Hummons, D., Commonplaces: Community Ideology and Identity in American Culture, State University of New York Press: New York, 1990.

[12] Stedman, R. Toward a social psychology of place. Environment and Behavior, 34(5), pp. 561-581, 2002.

[13] Relph, E., Place and Placelessness, Pion: London, 1976.

[14] Kim, J. \& Kaplan, R., Physical and psychological factors in sense of community: New Urbanist Kentland and nearby Orchard Village. Environment and Behavior, 36(3), pp. 313-340, 2004.

[15] Winkel, G.H. The perception of neighborhood change. Cognition, Social Behavior, and the Environment, ed. J. Harvey, Lawrence Erlbaum: Hillsdale, New Jersey, pp. 489-512, 1981.

[16] Stokols, D. \& Shumaker, S., People in places: A transactional view of settings. Cognition, Social Behavior, and the Environment, ed. J. Harvey, Lawrence Erlbaum: Hillsdale, New Jersey, pp. 441-488, 1981.

[17] Syme, G.J., Fenton, D.M. \& Coakes, S., Lot size, garden satisfaction and local park and wetland visitation. Landscape and Urban Planning, 56, pp. 161-170, 2001.

[18] Bonnes, M. \& Secchiaroli, G., Environmental Psychology: A Psychosocial Introduction, Sage: London, 1995.

[19] Strauss, A. \& Corbin, J., Basics of Qualitative Research: Grounded Theory Procedures and Techniques, Sage: London, 1990.

[20] Smaldone, D., Harris, C. \& Sanyal, N., An exploration of place as a process: The case of Jackson Hole, WY. Journal of Environmental Psychology, 25, pp. 397-414, 2005. 